\title{
Post-truth Politics and Collective Gaslighting
}

\author{
Natascha Rietdijk \\ Tilburg University, Tilburg, the Netherlands \\ Email n.w.rietdijk@tilburguniversity.edu
}

(Received 23 July 2020; revised 22 April 2021; accepted 4 May 2021)

\begin{abstract}
Post-truth politics has been diagnosed as harmful to both knowledge and democracy. I argue that it can also fundamentally undermine epistemic autonomy in a way that is similar to the manipulative technique known as gaslighting. Using examples from contemporary politics, I identify three categories of post-truth rhetoric: the introduction of counternarratives, the discrediting of critics, and the denial of more or less plain facts. These strategies tend to isolate people epistemically, leaving them disoriented and unable to distinguish between reliable and unreliable sources. Like gaslighting, post-truth politics aims to undermine epistemic autonomy by eroding someone's self-trust, in order to consolidate power. Shifting the focus to the effects on the victim allows for new insights into the specific harms of post-truth politics. Applying the concept of gaslighting to this domain may also help people recognize a pernicious dynamic that was invisible to them before, giving them an important tool to resist it.
\end{abstract}

Keywords: Post-truth; gaslighting; self-trust; autonomy

Ever since "post-truth" was elected as word of the year 2016, journalists, social scientists and philosophers have sought to understand the nature and dangers of the phenomenon this term refers to. Some have pointed to its negative effects on our knowledge (Levy 2017), others have connected it to Frankfurtian bullshit (Davies 2017), and still others have warned that post-truth rhetoric is detrimental to democracy (Fish 2016; Suiter 2016). Though it has been argued that the term "post-truth" is ambiguous and misleading (Habgood-Coote 2019), the factual existence of political discourses that exhibit a lack of concern for facts and expertise is undeniable - and epistemically problematic. Each of the above analyses captures important harms involved in that type of political discourse. However, I believe there is one more wrong involved which has not sufficiently been recognized yet. Post-truth politics does not just impair knowledge or democracy, it can also undermine our epistemic self-trust and thereby our epistemic autonomy. Because of this, and because of the techniques it employs to do so, I will argue it is remarkably similar to a form of manipulation known as gaslighting.

Gaslighting aims at having the victim doubt their own judgment, perception, and sense of reality. The term is primarily used to describe a form of interpersonal manipulation, though there is growing journalistic use of the term to describe contemporary political tactics (Dowd 1995; Caldwell 2016; Duca 2016; Carpenter 2018). This paper 
aims to develop a philosophically robust analysis of these ascriptions, that is, of describing "post-truth" politics as a form of gaslighting. In particular, it explores what gaslighting might look like in a political context, and in so doing, reveals important and overlooked dangers of post-truth politics. Importantly, I will argue these include harmful effects on epistemic autonomy. My view is not meant as a competing analysis of post-truth politics and its dangers, but as an extension of the existing analyses. Shifting the focus from democracy and knowledge to the effects on victims and their autonomy allows for new insights into some of the specific harms of post-truth politics, and the ways in which various types of post-truth rhetoric are in fact related. Often when speaking of post-truth, we think of the powerful and the arrogant - of those who have so much self-trust they feel they are above the facts. But there is another, perhaps bigger group of people who instead feel confused, disoriented, and powerless. For them, knowledge of factual truth may instead seem beyond their reach. Crucially, the concept of gaslighting might help them recognize a pernicious dynamic that was invisible to them before. Knowing what gaslighting is enables us to identify it when it is happening in front of us. That recognition might be a crucial first step in empowering people to resist gaslighting.

In the first section, I will give some background on the term post-truth and introduce three examples from contemporary politics. Each example represents one of three categories of post-truth rhetoric I will distinguish, all of which obscure truth, albeit in a distinct way. The second section outlines what gaslighting is, how it works, and why it works. By impairing a person's self-trust through deceit, manipulation and isolation, gaslighters not only violate their epistemic autonomy, but actually systematically erode it. In the third section, I further explain the three categories of post-truth rhetoric and how they, too, threaten epistemic self-trust and epistemic autonomy. I demonstrate how counternarratives are introduced to distract and confuse, how critics are discredited to undermine the difference between reliable and unreliable sources, and how blatant fact-resistance in some may lead to self-doubt in others. Each of these strategies might, under certain circumstances, get a victim to distrust at least some of their epistemic capacities. In the fourth section I draw out the implications of these similarities. Acknowledging some superficial differences, I show how studying post-truth politics through the lens of collective gaslighting is a mutually informative exercise. Considering its analogy to gaslighting, I conclude by pointing to possible ways in which to prevent, resist or remedy post-truth political rhetoric.

\section{1. "Post-truth" politics}

In July 2014, Malaysia Airlines Flight 17 was shot down over Ukraine. There were no survivors. At the time, the Ukrainian military was involved in an armed conflict with pro-Russian separatists in the east of the country. It was soon suspected that the passenger plane was taken down with a BUK missile system. Both parties denied involvement. Yet as the evidence stacked against the Russia-backed separatists and it was revealed the BUK system belonged to the Russian army, the Kremlin could not seem to settle on its story. It began with claims that the plane had been filled with dead bodies, that the plane had been a fake, and that the real target had been Putin's plane. Later it was claimed that $\mathrm{MH}-17$ was shot down by a Ukrainian jet, later still that it had been a BUK missile, just not a Russian one. Government employees, state media and unofficially state-run social media accounts and fake news websites all helped spread this disinformation. Six years after the crash, the Kremlin is still introducing new counternarratives blaming Ukraine as well as the international investigation team (EUvsDisinfo 2019). 
After weeks of raging forest fires in the Amazon, the Brazilian president Jair Bolsonaro fired the head of a government agency tracking deforestation. The agency had earlier disclosed the alarming rate at which the rainforest was shrinking. Bolsonaro defended his decision during a press conference, claiming people from within the government were trying to hurt the country's image: "The numbers, as I understand it, were released with the objective of harming the name of Brazil and its government." Around the same time he also dismissed his other most fervent critics, claiming NGOs were to blame for the fires, accusing the international media of "sensationalist attacks" and foreign critics of "colonialism" and of questioning Brazil's sovereignty (Philips 2019).

In 2011, long before he started running for president, Donald Trump appeared on a talk show, raising questions about Barack Obama's birth certificate. The "birther" issue, questioning Obama's place of birth, had by then mostly died down. "Why doesn't he show his birth certificate?" Trump had asked. "I wish he would because I think it's a terrible pall that's hanging over him ... There's something on that birth certificate that he doesn't' like" (Cheney 2016). During the following five years, he played a leading role in reviving the birther movement. He told Fox News he was "starting to wonder ... whether or not he was born in this country" (Carpenter 2018). He said Obama's grandmother was on tape saying he was born in Kenya. Even after the birth certificate was released, Trump continued questioning its authenticity. In 2014, he tweeted an invitation to hackers to find Obama's college records and check "place of birth." All the while, he kept denying that he was an actual birther. Five years after reviving the controversy, Trump called a press conference where he finally admitted the president was born in the US. But he was quick to deny any responsibility for starting the rumor, telling the press: "Hillary Clinton and her campaign of 2008 started the birther controversy ... I finished it, you know what I mean. President Obama was born in the United States period. Now we all want to get back to making America strong and great again" (Carpenter 2018).

Each of the above three examples could be and has in fact been described as an instance of post-truth politics (Berkowitz 2016; Pool 2018; Apps 2019). Post-truth has been connected to fake news (Levy 2017), Frankfurtian bullshit (Davies 2017), echo chambers (Nguyen 2020), tribal epistemologies (Rini 2017), rampant use of pathos in political rhetoric (Laybats and Tredinnick 2016), declining trust in traditional epistemic authorities (Ylä-Anttila 2018), and finally to a lack of belief in truth (Finlayson 2019). What these phenomena each have in common is a problematic relationship to truth. Truth, especially in the guise of facts and expert knowledge, is dismissed either as a dangerous fiction or as irrelevant. What we are left with is "post-truth" politics, which I broadly define as an epistemically dysfunctional type of discourse which is unconcerned with objective facts. Many more specific but conflicting definitions of "post-truth" have been given, which has led some to argue we should drop the term altogether (Habgood-Coote 2019). It is not my intention here to settle these issues. ${ }^{1}$ Neither will I be answering the question whether these forms of rhetoric are exclusively a contemporary phenomenon, although I suspect they may be somewhat more prevalent in current politics than in the past. Leaning on the broad definition given earlier, my objective is limited to expanding our understanding of what exactly is happening in the above examples and in similar interactions.

\footnotetext{
${ }^{1}$ While I am sensitive to Habgood-Coote's concerns, I believe there is more consensus about the use of the term than he suggests, especially in the more limited scope of cases I am interested in. There are others who have convincingly argued instead that terms like "fake news" still serve a function (Pepp et al. 2019). Those who dislike the term "post-truth politics" may substitute it with "epistemically dysfunctional political rhetoric" instead.
} 
I will categorize the kinds of cases I want to focus on into three subtypes: first, the introduction of counternarratives, second, the discrediting of (potential) critics, and third, the denial of a more or less plain fact. Each of the three examples at the start of this section represents at least one of these categories of post-truth rhetoric, but many other examples from contemporary politics could be given. Although these categories are distinguishable, they are not unrelated, and in some interactions they may overlap. It is even conceivable that all three categories are present in one single sentence, like in the case of Trump denying responsibility and blaming Hillary Clinton for the birther controversy in one breath. Crucially, all of these cases seem to obscure truth, but in slightly different ways, using different strategies. So why are these strategies so effective as political instruments, and why are they so dangerous?

Philosophers have so far identified various harms in supposed symptoms of the post-truth condition. Perhaps the most obvious consequence is the formation of false beliefs. Neil Levy (2017) cites psychological research to illustrate just how damaging fake news and misinformation can be. Even messages which are not intended to mislead or which we know to be untrue, do in fact often lead to us forming false beliefs. Contextual factors like our familiarity with a story may render it more easily acceptable, so that mere repetition of a false narrative can sometimes suffice to make people believe it. A second epistemic issue is the rise of partisan tribal epistemologies (Rini 2017; Nguyen 2020). Under the influence of echo chamber effects, groups of like-minded people develop their own epistemic authorities, their own ideas about what counts as evidence, and consequently, their own "knowledge." Outsiders are automatically distrusted, and important information is passed over. A final epistemic problem is identified by those who equate post-truth with bullshit (Ball 2017; Davies 2017; Kristiansen and Kaussler 2018). The bullshitter does not care about being truthful, but only about persuading their audience. Theirs is the vice of what Cassam (2019) calls "epistemic insouciance." Their vicious attitude means they are not only doing themselves no epistemic favors, they are also misleading others for their own personal gain. As these authors point out, the dangers of such rhetoric extend beyond matters of knowledge, as they can potentially have serious political consequences.

Many theorists have tried to spell out the socio-political consequences of various post-truth practices, specifically, the threat they pose to democracy. There are multiple versions of this argument, all holding that in a post-truth society one or more of the conditions for legitimate democracy are undermined. Various authors have argued that post-truth politics undermines the trust in institutions (Suiter 2016), and general transparency that are fundamental to democracy's proper functioning. The latter view is also articulated by Fish (2016), who emphasizes the significance of informed consent for the democratic practice of voting. He argues that the legitimacy of a democratic government's power derives from its being chosen freely by the citizens. However, a voter can only really give their consent if important information regarding the policy or politician they vote for is neither withheld nor misrepresented. Fish states that playing "fast and loose with the truth" (2016: 211), obstructs the attitudes and practices that are needed for citizens to be properly informed. He concludes that post-truth politics is unable to "provide anything other than illusory democracy" (2016: 212).

Each of these analyses rightly identifies a harmful consequence of post-truth politics and the three subcategories I have distinguished. Counternarratives will often contain bullshit and, if repeated enough by politicians and the press, they will lead to false beliefs which in turn undermine informed political consent. Discrediting plays a central role in the formation of echo chambers as it reinforces distrust of outsiders, as well as eroding trust in experts and in institutions. Finally, denial of plain facts and selfcontradiction is emblematic of the bullshitter's opportunistic attitude. Yet there is 
one more analysis of the rhetoric exemplified in these cases. Post-truth politics is not just an expression of disregard for truth or an origin of false beliefs; it can also undercut our own faith in our capacity to distinguish between truth and falsehood, between reliable and unreliable sources. In this regard, it is similar to gaslighting - and an analysis in terms of gaslighting can help us identify a further harmful effect, namely the undermining of epistemic self-trust and thereby epistemic autonomy.

This is not the first time that the concept of gaslighting has been connected to political practices. Various journalists and writers have accused politicians of gaslighting opponents or citizens to gain power (Dowd 1995; Caldwell 2016; Duca 2016; Behr 2018). The three examples at the start of this section, labeled instances of post-truth by many, have also been identified as gaslighting by others (Carpenter 2018; Kahn 2019; Lewandowsky 2019). The Kremlin, Bolsonaro, the Trump administration, the Clintons, the Brexit campaign team, and even political journalists themselves - they have all at one point or another been connected to gaslighting practices. My aim in the remainder of this paper will be to investigate to what extent these accusations are on to something, specifically, in what regard knowledge of gaslighting can help us understand and combat certain dangers of post-truth politics. In the third section I will use the concept of gaslighting to highlight the impact that various forms of posttruth political rhetoric can have on epistemic autonomy. Before doing so, I will give an overview of what gaslighting is and what its consequences are.

\section{What is gaslighting?}

The term "gaslighting" is derived from the 1938 Patrick Hamilton play Gas Light and its two film adaptations, in which a Victorian husband attempts to have his wife diagnosed as mentally ill and taken away to an asylum so that he can obtain her fortune. He deceives her to make her believe she is becoming increasingly forgetful, and when she tells him about the footsteps she hears overhead at night, or about the gaslights in her room that she has seen dim suddenly, he convinces her she has been hallucinating. As a matter of fact, the footsteps and dimming lights were real, direct consequences of him searching upstairs for the expensive jewels his wife inherited. Since the 1960s psychologists have started using the term to refer to the real-life equivalent of the phenomenon depicted in the play and film (Barton and Whitehead 1969). Gaslighting is now commonly defined as a type of manipulation aimed at having the victim doubt their own judgment, perception, and sense of reality (Stern 2007; Abramson 2014). In severe cases, like the one Hamilton portrays, this will cause the victim to question even their own sanity, leaving them feeling disoriented and confused at best, and desperate and depressed at worst. While the play sketches a paradigm example of the phenomenon, it is not necessarily representative of most real-life gaslighting interactions.

Two examples from the literature illustrate well what gaslighting typically looks like. The first is from psychologists Gass and Nichols (1988: 6) who cite the following exchange between a woman and her unfaithful husband:

The worst part, Harry, is the lying!

I'm not lying, you're just imagining things!

The authors use the example to show how gaslighting can be used as a defensive strategy by cheating spouses. Instead of engaging with his wife's accusation, Harry denies having an affair and accuses her of making things up. The second example, given by philosopher Kate Abramson (2014: 5), describes the experiences of a female graduate student: 
I moved out of one field of philosophy in grad school due to an overwhelming accumulation of small incidents ... When I tried to describe to fellow grad students why I felt ostracized or ignored because of my gender, they would ask for examples. I would provide examples, and they would proceed through each example to 'demonstrate' why I had actually misinterpreted or overreacted to what was actually going on.

Again in this example, the victim voices legitimate criticism but is told she misinterpreted the situation. "You're just overreacting/being unreasonable/crazy/overemotional/ jealous/irrational ...": these are the typical gaslighter's defensive responses to some form of disagreement (Stern 2007; Abramson 2014). And while some of these retorts may seem too banal to be considered harmful, context matters. One such incident may be painful but it might not influence a victim's self-confidence. However, if someone is repeatedly told, perhaps even by multiple people, that they misinterpret intentions, are being overly suspicious, or even paranoid, they will likely start doubting their own perceptions and judgments. That is what gaslighters want to accomplish. Gaslighting is not an incident, but a process, an attempt to steadily undermine a person's epistemic self-trust through manipulation, deceit, or both (Spear 2019). But what does that mean, how does it work, why does it work, and why would anyone want to do it?

Let's start with the target of gaslighting, the victim's epistemic self-trust. According to Zagzebski (2012) and Spear (2019), this is the basic belief that my cognitive faculties are overall reliable, that they generally deliver accurate data and that I am able to correctly form true beliefs on the basis of them. It entails trust in my own senses, memory, and reasoning capacities. It is usually a tacit belief, it is a belief that most of us have quite naturally or intuitively, and it forms the basis of any meaningful epistemic agency. If my epistemic self-trust is damaged, I will have little confidence in my own beliefs - if it is eradicated, I will have no basis on which to form beliefs at all. Following both authors, I take gaslighting to be just that: the practice of trying to undermine a person's self-trust so that they no longer consider themselves to be a reliable source of judgment and deliberation. Zagzebski specifically says that a loss of general self-trust "would threaten to destroy the self" (2012: 62n8) and on Spear's account, this means a victim is "no longer able to meaningfully go forward as an [epistemic] agent" (2019: 17). While this seems right to me, I think the most precise way to describe what happens as a result of the gaslighting victim's loss of self-trust is that their epistemic autonomy is undermined. $^{2}$

Epistemic autonomy is itself a contested term. I will here build upon Zagzebski's account. She argues that autonomy does not consist in self-reliance, as has been suggested by others (Fricker 2006), but in self-governance. To be epistemically autonomous cannot mean to never, or only rarely believe anything on testimony. Rather, it is often necessary to rely on others, especially when those others are epistemic authorities. Zagzebski uses the term autonomy to designate what we do when we are "conscious of being self-conscious" (2012: 230). In the intellectual realm, this means to be epistemically conscientious, or to exercise my faculties to the best of my abilities to get the truth. Epistemic or intellectual autonomy requires that we reflect on what to believe and whom to trust; that we conscientiously identify and manage epistemic authorities (2012: 250). Zagzebski concludes that "from the outside, then, autonomy is noninterference. But from the inside, autonomy is often the choice of interference, done

\footnotetext{
${ }^{2}$ Something like this is hinted at by Spear and Zagzebski, but not made explicit. I think it is more precise because the loss of epistemic autonomy occurs in any case of successful gaslighting, whereas the consequences mentioned here would only be at stake in the most severe cases.
} 
intelligently" (2012: 236). Autonomy fundamentally depends on self-trust in my own faculties. If my self-trust is damaged, my epistemic autonomy suffers. This is the case with all successful gaslighting attempts. They do not just violate autonomy, but erode it steadily and sometimes lastingly. In more everyday terms, the loss of epistemic autonomy means confusion, disorientation, a feeling that you are going crazy, and an increasing dependence on others. Again, in the most severe cases, it amounts to the loss of any meaningful (that is, autonomous) epistemic agency, the destruction of the self, or indeed clinical depression.

Gaslighting interactions can take many forms. They can consist of direct yet disingenuous accusations like in the examples cited above, of various forms of deception and confusion, or of more or less explicit manipulative threats and leverage. Many gaslighting attempts, and I suspect almost all successful attempts, will involve a combination of strategies. In the movie Gaslight, for instance, gaslighter Gregory doesn't just go up to his wife Paula one day telling her, out of the blue, that she is crazy. The manipulation goes on for months. He starts by moving things around in the house to confuse her. $\mathrm{He}$ hints that she has been overtired lately. He puts his own pocket watch in her purse, making her believe she stole it and forgot, and triggering a public scene. He then uses that incident to further isolate her so she doesn't talk to anyone but him. He starts denying that the gaslight dimmed, even though she clearly saw it. Meanwhile, he uses their love and her fear of abandonment as further manipulative leverage for her to go along with it. Only at the very end does he actually tell her she is going mad. Gregory is an exceptionally sophisticated and calculating manipulator, and not all gaslighters will use all of these strategies or use them in the same order. However, all of these elements - confusion, lying, deception, isolation, denial, accusation and manipulation, are part of the gaslighting process (Abramson 2014; Spear 2019). Each of them help the gaslighter to undermine the epistemic self-trust of their victim. While none of them are necessary for gaslighting, they form a mutually reinforcing set of strategies and their combined use in ascending order of severity is what makes the gaslighting in Gaslight effective.

There is another important factor in gaslighting contributing to its effectiveness: the victim trusts their manipulator and/or depends on them in some way (Abramson 2014: 19-20). Virtually all gaslighting cases described in the psychological literature involve romantic partners, friends, family members, co-workers or employers and employees. This is because gaslighting can only work if the victim is epistemically, emotionally or prudentially predisposed to believe the gaslighter. You trust them when they claim you misinterpret things, because they love you, or because they probably know better anyway. Or you may want to agree with them in order to avoid conflict, because they might otherwise leave you, or fire you. In these relationships of trust or dependency, it can appear to the victim that they are best off trusting the one person who pointed out their fallibility in the first place. Not only must the gaslighter have been in a better epistemic position in order to recognize this fallibility, they also cared enough to tell you about it and might even offer help. In fact, of course, trusting the gaslighter's claim will only strengthen the dependency of the victim and further erode their autonomy. Gaslighting is thus parasitic on a vulnerability that is inherent in trust relationships, exploiting the trust of the victim to have them distrust themselves and anyone who might restore their self-confidence. This arguably is one of its most pernicious features, and one that makes it particularly difficult to resist gaslighting efforts. I will return to the challenges of resistance at the end of this paper.

That leaves the question of why gaslighters do what they do. What could be the purpose of having someone else lose their self-trust? Gregory has a clear endgame in mind: getting rid of Paula and stealing her fortune. A whole host of similarly specific aims and conscious or unconscious desires could ultimately motivate gaslighters (Abramson 
2014). Gaslighting as it is portrayed in the psychological and philosophical literature is often used defensively, as a way to cover up other abuse, or, in Harry's case, infidelity. More generally, it is a way to deflect criticism or other undesirable views, as in the example of the grad students. ${ }^{3}$ Abramson argues that gaslighters have an "inability to tolerate even the possibility of challenge" (2014: 9). They are not satisfied with just ignoring someone who disagrees, or even by having everyone else ignore or disbelieve them. Instead, they need that dissenter to not have the standing to issue challenges at all, and to not see themselves as having that standing. Abramson concedes that some gaslighters may be satisfied when their victim's confidence is reduced enough for them not to issue any serious challenges anymore on a limited scope of topics. But she also rightly warns that self-doubt in one arena of life can easily spread to others, and that "where gaslighting is going on, it is often pervasive" (2014: 18). In the end, one of the central purposes of gaslighting is always to control the victim. As discussed, the loss of epistemic autonomy is the inevitable consequence of undermining someone's self-trust. Victims grow dependent on the gaslighter and possible accomplices for determining what and whom to believe. It is then perhaps unsurprising that some politicians have started implementing gaslighting techniques.

\section{Post-truth politics and the loss of self-trust}

Knowing the dynamics of gaslighting enables us to see the three subtypes of post-truth rhetoric in a new light. The introduction of counternarratives, the discrediting of (potential) critics, and the denial of a more or less plain fact each resemble gaslighting strategies. My aim in this section is to outline exactly what is going on in these categories of epistemically dysfunctional political rhetoric, and to show how they, too, aim to undermine epistemic autonomy through damaging self-trust. On any plausible definition of epistemic autonomy, deceptive counternarratives, discrediting and denial would count as manipulative and a serious threat. Zagzebski's account is however particularly well-equipped to explain how these strategies break down the trust and selftrust essential for autonomous epistemic agency. All of this is not to say there are no other forms of post-truth politics, or other effects besides the impact on epistemic autonomy. Different people respond differently to different interactions, and context matters. Some may experience a rise in self-trust when, say, their political opponents are being discredited and their own opinions are validated. ${ }^{4}$ Many, however, lose confidence when confronted with inconsistent and disorienting information. It is the latter effect which I will be exploring here.

The first type of post-truth politics I identified is the introduction of counternarratives. These can be realistic or farfetched, but they always contradict the dominant existing story. Putting an alternative account out there can help to mislead, but mostly to distract and confuse the public. All of these consequences are helpful for the person or institution on whom the actual truth reflects badly. The Russian government often uses this tactic as a form of propaganda. The disinformation around the MH-17 crash is an instructive example. The kind of stories that were spread were so extreme and oftentimes so contradictory that they did not seem directed at convincing people so much as at disorienting them. It is difficult to provide persuasive evidence of noninvolvement, especially if you were in fact involved, but it is much easier to sow doubt. The truth is often nuanced, messy, and sometimes boring, so distracting attention with

\footnotetext{
${ }^{3}$ In this context, Abramson notes that gaslighting can be motivated by neutral or basically good needs, like the need to see the world as kind, to admire authority figures, or to maintain harmony.

${ }^{4} \mathrm{Cf}$. Beerbohm and Davis (Forthcoming), who make the increase rather than the loss of confidence central to their analysis of political gaslighting.
} 
an exciting and outrageous fiction is usually quite simple. This psychological fact explains the effectiveness of fake news. The more such counternarratives are out there, the more people will start questioning the truth and whether or how they can tell what is true in the first place.

How exactly does this affect self-trust and epistemic autonomy? Mainly it is because counternarratives distract, disorient, and confuse. The average citizen will find it difficult to tell whether flight $\mathrm{MH}-17$ was shot down by pro-Russian separatists or by pro-Ukrainians who merely wanted to make the separatists seem guilty. The more conflicting stories are out there, the more overwhelming it will be. The main obstacle to epistemic autonomy here is pollution of the epistemic environment with nonsense, ${ }^{5}$ making it hard for agents to trust that their epistemic abilities are fit for getting them to the truth. Because, as Zagzebski puts it, "the faculties I rely upon in forming beliefs operate on an environment, so trusting my faculties includes trusting that the environment is appropriate to the faculties" (2012: 37). In response it may be argued that counternarratives about one such specific event, even if they make me feel that I don't know what to believe anymore, will not often influence my general trust in my epistemic abilities. But as indicated in the previous section, self-doubt can easily spread to other domains, and political narratives like these rarely take place in a vacuum. If the Kremlin manages to have me entertain the possibility that pro-Ukrainians would shoot down a passenger plane to make the Russians look bad, that might have me doubt whether my own government hasn't been feeding me anti-Russian propaganda all this time. And if I have falsely trusted them, what else have I been mistaken in? And finally, all of this depends on the context. The counternarratives must have some plausibility to the victim and they work best when combined with other post-truth strategies like discrediting, as the $\mathrm{MH}-17$ example illustrates.

This, the discrediting of critics is the second category of post-truth rhetoric. Sometimes this happens on an individual level, when political opponents or critical journalists or scientists are dismissed as delusional, paranoid, or jealous. The first person to use the term gaslighting in a political context actually describes how this happened to Newt Gingrich. The then Speaker of the US House of Representatives was repeatedly provoked to anger by members of the Clinton administration in an effort to make him appear "hysterical" (Dowd 1995). However, it is more common that critics are not discredited as individuals but as part of a corrupt institution. Here, President Trump's generous use of the "fake news" label and claim that the press is the enemy of the people come to mind. It is a clear attempt to dismiss, or at least cast doubt upon the trustworthiness of a specific newspaper or a whole range of mainstream media. Scientific and academic institutions have also been subject to this treatment, as the example of Bolsonaro and the mapping of forest fires shows. Far-right parties in Germany and the Netherlands called upon students to report "leftist" teachers, claiming schools and universities are instruments of leftist indoctrination. In 2011, conservative radio host Rush Limbaugh even branded government, academia, science, and the media "The Four Corners of Deceit." All of these examples show how discrediting is used to sideline and silence those individuals and institutions that tend to disagree. Accusations range from widespread unintentional bias to evil conspiracies. Very often, post-truth strategies will be used to discredit critics, especially traditional institutions of epistemic authority, as incompetent, untrustworthy, or both.

\footnotetext{
${ }^{5}$ The application of environmentalist language to an epistemological context is argued for by Ryan (2018). He counts everything that is counterproductive to the acquiring and sharing of knowledge as epistemic pollution. I think the label works especially well for the spread of lies and bullshit. See also Blake-Turner (2020), who discusses the degradation of the epistemic environment due to fake news.
} 
The effects of such discrediting are manifold, but the ones relevant to epistemic autonomy are the following. First, in the case of individual discrediting, it may be the critic herself who is the victim of gaslighting. They can lose trust in the justification for their criticism, as well as in their own motives. But when whole institutions are under fire, they rarely suffer a loss of self-trust as a consequence of these attacks. There, the main victim is among the public. Where experts' authority is questioned for the wrong reasons, those who would normally rely on their expertise are epistemically isolated. This is the second relevant effect of sidelining critics, and one that is also often used in one-on-one gaslighting. It affects epistemic autonomy directly, because the manipulation of trust inhibits the victim's ability to conscientiously and freely manage and identify authorities. But their epistemic autonomy also suffers because of a loss of self-trust. Most of the discredited institutions are traditional epistemic authorities which are trusted by the general public. When this trust is allegedly shown to be unfounded, the public will start to doubt their own ability to tell who is a trustworthy authority. Or, as Zagzebski describes it, "an attack on a person's trust in others is also an attack on her trust in herself. If someone's trust in another is destroyed, she realizes that she cannot trust her own trust; she cannot trust what she trusts, and that includes herself" (2012: 237). The ability to identify authorities is a crucial epistemic capacity, and once I start questioning it, my epistemic self-trust - and thereby my epistemic autonomy - decreases. Moreover, by cutting off people from those sources that might restore their self-trust, their ability to think critically and their autonomy, manipulators further enhance their victims' dependency.

The third and final category of post-truth rhetoric I have identified is the denial of a more or less plain fact. There are many examples of this in contemporary politics, including climate change denial and birthers' denial of their own birtherism. Most striking are those cases in which a politician denies having said or done something which was actually captured on record just days earlier. Donald Trump's expertise at this has been well documented, leading Carpenter (2018) to make it a key step in her account of his style of political gaslighting. The primary aim of such denial is usually pragmatic: to save face, or to not have to take responsibility for the past statements. More interesting are instances where what is denied is a certain interpretation of what was said or done, or the intention behind it. For example, Dutch politician Thierry Baudet made some controversial statements about the role of women in contemporary society. When asked about these statements he rejected their literal interpretation, saying he only made them in the context of a book review. Meanwhile, most of those statements echo similar extremely conservative claims he had made before in different contexts. This kind of denial is more subtle, because it is difficult to prove the intended meaning behind a message. It is also more dangerous, because it allows politicians to make statements designed to convey a message to supporters, which is still ambiguous enough to deny to others that this was in fact the intended message. This more sophisticated denial has also been used by Trump supporters who insisted that Trump should be taken "seriously, not literally," or that his retweets of falsehoods should not be taken as endorsements of the original message (Carpenter 2018). The burden is on the audience to always choose the most charitable interpretation, while the speaker gets to be as ambiguous as is convenient for them, using dog-whistles and fig leaves as they like. ${ }^{6}$ It is

\footnotetext{
${ }^{6}$ Dog-whistles are the use of coded language which on the surface seems to mean one thing, but has an additional, often politically incorrect, meaning for the targeted audience. Because the communication is coded, it is easy to deny the underlying meaning. Saul (2017) uses the term 'fig leaf to designate utterances which provide cover for attitudes that would otherwise be deemed unacceptable, like a misogynist insisting he loves his mother.
} 
the perfect way to test more radical ideas or to stir up emotion without taking the corresponding responsibility.

The problem with such denial is not only that it is opportunistic and covers up socially unacceptable attitudes like sexism, racism and fascism, or unfortunate mistakes. It is also extremely confusing for the audience. When politicians, whom many people look up to, admire and trust, contradict themselves with so much confidence, it is not surprising when citizens start questioning whether they just heard that correctly, and possibly conclude that they have misunderstood. In all of these cases, the implicit or explicit suggestion is that the audience has misinterpreted or even misheard the message. Again, the epistemic autonomy of the listener is undermined through the erosion of their self-trust. This more subtle form of rhetoric is especially effective, since supporters can get what they want from the ambiguous communication, while opponents have nothing to grab on to. But those who have not chosen sides so decisively yet are left to wonder whether their ability to read tone and intent is functioning well enough for them to successfully navigate the politico-epistemic domain. It may seem unlikely that more extreme cases where plain facts are blatantly denied will have any effects on self-trust. But for those who are already confused and disoriented, such a move might actually lead them to question their own senses and sanity, especially if others around them act as if nothing strange has happened or even repeat the denial.

Thus, by introducing counternarratives, discrediting critics, and denying facts, politicians can undermine the self-trust of citizens and thereby their epistemic autonomy. One might object that, at least in some of the cases I have described, the loss of self-trust is not the most rational or the most natural response. ${ }^{7}$ Perhaps the best response to an epistemically polluted environment is a suspension of judgment. ${ }^{8}$ I think that is largely true. Spear (2019) argues that it is almost never rational to go along with the belief that I am generally untrustworthy, because self-trust is so fundamental to (epistemic) agency. However, it is not necessarily irrational to lower one's self-trust in a specific domain if given good reasons to do so. The point is that such a rational self-assessment as less competent might manifest as feelings of self-doubt, which in turn can easily spread to my assessment of my epistemic competency in other domains. This is especially the case if I trusted my competencies before, because it may lead me to question what other abilities of mine could be compromised. Gaslighting is a slow and insidious process, which can start with a rational and domain-specific lowering of confidence and progress into a general loss of self-trust. More importantly, though, Spear concedes that it will be difficult for victims to be rational under the circumstances that gaslighters create, which are usually deceptive and laced with manipulative threats and leverage.

That brings us to the question whether a loss of self-trust is the most natural or likely response in the cases I've sketched. Here the answer will depend both on the personality of the victim, how prone they are to self-doubt, and the specific circumstances. Note that the proneness to self-doubt will often be conditioned by societal forces and expectations. Those who structurally suffer testimonial injustices, for instance, will typically also be more vulnerable to gaslighting. As with individual gaslighting, conducive cirumstances include relationships of dependency, trust and authority, the repetition of certain narratives both over time and by multiple sources, and the weight of the topics. In the cases I have described, the perpetrators have political authority over the victims. Just one instance of their forms of rhetoric may not be very impactful, but the cumulative effect of such acts over time can be very harmful. They rarely concern isolated problems, but rather whole political narratives, which are tied up with world views, ideologies and

\footnotetext{
${ }^{7}$ I want to thank an anonymous reviewer for raising this point.

${ }^{8}$ Though note that such agnosticism would still be an epistemically harmful effect of these strategies.
} 
political identities. In other words, these are not domains about which it is easy to remain agnostic. Crucial is also that many around the victim will contend that the truth is, in fact, plain, and so that I am at fault if I want to suspend my judgment. The fact that so many people are confidently asserting their opinions is in fact part of the post-truth conundrum.

Finally, each of the forms of rhetoric I have identified also reinforces the success of the other: if I can introduce a counternarrative that denies a more or less plain fact and simultaneously discredit those who know and tell the truth, I am much more likely to succeed and damage people's self-trust. Revisiting the examples at the start of this paper, we can see that they, too, use a combination of strategies: the Kremlin discredited Bellingcat as a way to deny their own complicity in the $\mathrm{MH}-17$ crash, all while conducting a great misinformation campaign. Jair Bolsonaro denied the problem of forest fires by discrediting an authority, claiming the numbers were exaggerated to harm Brazil's image. Donald Trump denied being a birther before falsely blaming Hillary Clinton for starting the rumor. These strategies are all part of the same process aimed at undermining epistemic autonomy through undermining self-trust and together, they are more likely to clear the path to further control. ${ }^{9}$ Because the final aim of the post-truth politician is to consolidate power. It is the combined use of different strategies of political rhetoric in order to achieve this goal that make it so very similar to gaslighting. I will further draw out these similarities and their implications in the next section.

\section{Collective gaslighting}

There is significant overlap between gaslighting and the categories of post-truth politics discussed above. They can both undermine epistemic autonomy, specifically through impairing the victim's self-trust in their epistemic abilities. Victims are made to feel confused and disoriented through the introduction of counternarratives. They may also question their own ability to find out the truth in such a polluted epistemic environment. They are epistemically isolated by the manipulation of trust and the discrediting of critics, making them doubt the appropriateness of their trust and their capacity to ascertain trustworthiness. Finally, they are moved to even question their own senses, memory and reality when faced with blatant denial. Each of these strategies of deception, disorientation, isolation and confusion used in post-truth politics resembles those used in traditional, one-on-one gaslighting (Abramson 2014; Spear 2019). While they can be used independently, they mutually reinforce one another's effectiveness, just like Gregory could only have Paula believe she was going crazy by first hiding his watch to confuse and deceive her, and then isolating her from her friends and acquaintances. If there is such a thing as collective gaslighting, where a whole group of people is victimized, it would look very much like this.

Of course, there are a number of ways in which post-truth politics appears to be different from traditional gaslighting. The relationship between perpetrator and victim is not a personal one. The person suffering a decrease in self-trust is not even always the direct target of the political rhetoric, but sometimes a third party. Lastly, having someone doubt themselves only rarely seems to be the aim of post-truth discourse. More often, garnering political support is the real goal. The loss of self-trust may not always seem like a primary or even a plausible consequence - some people may instead feel bolstered in their self-trust when their opponents are silenced. It is important to

\footnotetext{
${ }^{9}$ Another way to conceptualize political gaslighting is to think of it as consisting of multiple steps. This is Carpenter's (2018) approach to analyzing Trump's "gaslighting method". Although I think it is fruitful to analyze gaslighting as a process in which various strategies can be combined, I do not believe we should think of any of these strategies as necessary steps occurring in a set order.
} 
acknowledge these differences. There is a concern that stretching the meaning of gaslighting beyond severe psychological manipulation could amount to conceptual inflation. $^{10}$ Not every loss of self-trust is proof of gaslighting and I agree that it would be offensive to victims to use the term too lightly.

However, the differences between the categories of post-truth rhetoric I am interested in and individual gaslighting may not be as significant as they appear. Although the relationship between victim and perpetrator is not a personal one, it is still in the relevant ways one of trust and dependency, the factors that are central to most gaslighting cases. The manipulator holds power over the victim just by virtue of the political office they hold, and the respect and admiration this office may command. The fact that the victim of gaslighting is not always the only or even the primary interlocutor makes post-truth politics more complex, but does not set it apart from individual gaslighting. In an effort to epistemically isolate their victim, gaslighters will often recruit accomplices, while cutting off their victims from potential allies like family and friends. ${ }^{11}$ This is an important part of the process in individual gaslighting because allies are a lifeline, a link to reality and a source of self-trust. Something very similar is at stake where epistemic authorities like scientists and journalists are sidelined by politicians. The role of accomplices may also explain how those experiencing heightened self-trust fit into the picture: they are not the victims of gaslighting, but they support the gaslighter's goals and use their language. When a politician denies a plain fact they will go along with it, adding to the victim's sense of confusion and isolation. These accomplices may not be affected by the gaslighting rhetoric but they are still part of the story.

Finally, when it comes to their aims and consequences, post-truth rhetoric and individual gaslighting are again equally complex. As Abramson notes, gaslighters often have multiple aims, which may be conflicting, and some of their underlying motives are typically obscure even to themselves $(2014: 8,11)$. Political gaslighters may want to push through a policy without too much resistance, they may want to win an election or save face after losing one, or it could be in their best interest to oppress part of the population. But as with individual gaslighting, one of the central underlying motives seems to be about gaining and keeping power. Reducing someone's epistemic self-trust is not typically a goal in itself. Its plausibility, just as in cases of individual gaslighting, depends on the context: the specific power and authority that the perpetrator already has over the victim, and the various other techniques and accomplices they may have at their disposal. But where facts are denied and opponents are discredited, the loss of self-trust suffered by the victim is rarely just a side effect. What post-truth politicians are after is control, and, whether they are fully aware of it or not, it is achieved by silencing dissent, obscuring inconvenient facts, and disorienting people so much they long for securities and strong leadership. Gaslighting is just one of the means to this aim.

Moreover, the question of how exactly we label the phenomenon I have drawn attention to is not the critical issue here. What matters is that, like gaslighting, the three categories of post-truth politics I have identified can undermine people's self-trust. They have the same potential effects on epistemic agency, using the same strategies for sowing doubt and ensuring epistemic isolation. Regardless of whether this post-truth rhetoric is a proper form of gaslighting or rather a technique contributing to gaslighting effects, the very concept of gaslighting has allowed us to see how these strategies are effective, and indeed part of the same process. Applying the concept of gaslighting to the discussion on post-truth politics sheds new light on its nature and its dangers. These go beyond the effect on knowledge and the threat to democracy. One central problem with post-

\footnotetext{
${ }^{10}$ This is exactly what is argued by Case (2019).

${ }^{11}$ For examples of gaslighting where multiple parties are involved, see Stern (2007) and Fricker (2017).
} 
truth rhetoric is that it can undermine our epistemic autonomy, our ability to find our way in the realm of knowledge, and our capability to manage authorities. Shifting our attention to the impact on victims thus allows for new insights. Not only does it inform our understanding of post-truth politics, it also informs our understanding of what exactly gaslighting consists in and what heretofore unknown forms it may take. The rhetoric of blatant contradiction, for instance, is much more often recognized as gaslighting than the introduction of counternarratives or the discrediting of critics, and this may apply in the individual realm too. Furthermore, it highlights important features of gaslighting, such as the fact that it is a process usually made up of multiple strategies which are not only connected, but more harmful when combined.

But there is also a practical import. The concept of gaslighting is crucial for recognizing a very specific form of manipulation and oppression. First, access to the concept resolves the hermeneutical injustice of victims not having the words to describe the wrong being done to them (Fricker 2007). Second, knowing about gaslighting can also help arm potential victims against its harms. If someone, be they a close acquaintance or a politician, makes you feel like you cannot keep up, like you are losing touch with reality, it may not be you who is the problem. Familiarity with the dynamics of gaslighting is thus a first step in resisting it (Abramson 2014: 28). Moreover, seeing the similarities between post-truth rhetoric and gaslighting suggest that we may look to the literature on gaslighting to find other ways to prevent and combat it. Spear (2019) for instance argues that because of the importance of self-trust for agency, a person should only ever concede her epistemic self-trust for well-credentialed epistemic reasons. Awareness of this epistemic norm might also help a potential victim of gaslighting to resist. Other individual recommendations from psychological literature include attempting to "identify the problem," "sort out truth from distortion," reconnect with one's intuitions and detach from the gaslighter. In terms of concrete behavior, victims are advised to "keep talking to trusted friends," and finally, be willing to leave (Stern 2007; Hartwell-Walker 2018). Carpenter's Trump-specific advice boils down to staying critical while refusing to engage and play along (2018).

Most of these authors however concede that there are often circumstances which make it particularly difficult for victims to rationally resist the undermining of their self-trust. As Abramson (2014: 28) emphasizes, “one doesn't decide to go along with gaslighting; one finds oneself gaslighted." She herself draws attention to the role sexist stereotypes play in gaslighting, and Spear suggests looking closely at "the social conditions and types of character that we should seek to cultivate and allow to flourish in order to make its [gaslighting's] use and success less common and less likely" (2019: 22). Gaslighting thrives best in cases of power asymmetry (Spear 2019; Sweet 2019). Reducing power imbalances renders people less vulnerable to it. This could mean more transparency, accountability and accessibility both in politics and in traditionally authoritative epistemic institutions.

It may not be obvious for all of these recommendations how they should translate to political gaslighting. Recognizing the problem and trying to fact-check seems straightforward enough. Not caring about the gaslighter's opinion and ending the relationship is more difficult when that person has great political power. Then again, when you feel that post-truth political rhetoric has great emotional impact on you, choosing to limit your news consumption and refusing to argue on their terms could be helpful. Researcher and therapist Robin Stern tells her patients to determine whether a conversation with the gaslighter is really a power struggle, and if it is, to opt out (2007: 110). The advice to stay connected to one's intuitions makes sense, but is also problematic against the background of emotions being valued over facts. The same goes for staying in touch with trusted friends, when those friends are mutually accusing one another of being untrustworthy. It will always be difficult to identify a gaslighter, although the 
discussions in this paper may provide us with some clues. Perhaps most helpful is the recommendation to consider the social conditions of self-trust. As individuals, we should not give up our trust in those institutions that are optimally epistemically positioned to check and criticize politicians. As a society, we should try to encourage and equip people to develop intellectual confidence and not let themselves be epistemically isolated. These are only rough sketches of possible remedies, which deserve to be worked out more fully than I am able to do here. For now, I hope at least to have contributed to that crucial first step in combatting gaslighting: to identify the problem.

\section{Conclusion}

My main goal in this paper has been to investigate what the concept of gaslighting can teach us about the dynamics and dangers of post-truth politics. I described three central examples and identified the three categories of post-truth rhetoric that they represent: the introduction of counternarratives, the discrediting of critics, and denial of a more or less plain fact. While the existing literature has identified the harmful effects of this rhetoric on our knowledge and on democracy, its effects on epistemic agency were under-studied. I then went on to show that, like gaslighting, each of the three categories of post-truth rhetoric undermines the epistemic self-trust and thereby the epistemic autonomy of the audiences. And it was not just these consequences they turned out to have in common. The techniques used: of deception, disorientation, isolation, and confusion, and the aim of consolidating power by silencing dissent, are analogous too. The framework of gaslighting helps us to see the interconnectedness of these strategies: they are all part of the same process, and they reinforce one another's effects. I ended by drawing out the implications of all these similarities.

The most important conclusion to be drawn from all this, is that there is another harm of post-truth politics that has not sufficiently been recognized yet. Besides frustrating the acquisition and sharing of true beliefs and thwarting the foundations of democracy, some forms of post-truth politics can also undermine epistemic autonomy. That is a harm in itself, but it can in turn negatively affect democratic processes, the spread of knowledge, personal autonomy, and wellbeing. A second upshot is that gaslighting may be more complex and more diverse than most standard examples concede. There may be multiple parties involved, the target of the gaslighting may not be the direct target of the rhetoric, and there can be many motives behind the manipulative behavior. Finally, there are practical implications for how we should deal with post-truth rhetoric. Many have pointed out that fact-checking alone is insufficient or even counterproductive. Nguyen (2020) suggests we should form trust relationships to help people escape the echo chamber. Resources on gaslighting can serve to remind us that trust relationships actually render us vulnerable to manipulation when the trust is asymmetrical or exclusive. They offer other recommendations, such as refusing to engage, reducing dependency, and providing people with the right societal conditions for self-trust. Applying these recommendations to the political sphere, however, requires further research into the differences between the individual and collective forms of gaslighting, and how to characterize the respective mechanisms of manipulation. Moreover, there remain important questions about the social nature of epistemic self-trust, the relation between post-truth politics and epistemic overconfidence, and the role of old and new media as accomplices. The analysis of post-truth politics as a form of gaslighting developed here can serve as a starting point for investigating these important issues. ${ }^{12}$

\footnotetext{
${ }^{12}$ This paper has benefitted from discussions with participants at The Politics of (Post) Truth conference, the 2018 OZSW conference, the 2019 RANT Workshop, and the conference Knowledge, Citizenship,
} 


\section{References}

Abramson K. (2014). 'Turning up the Lights on Gaslighting.' Philosophical Perspectives 28, 1-30.

Apps P. (2019). 'Conspiracy Theories Are New Currency of Post-Truth Politics.' The Sydney Morning Herald, 23 August. https://www.smh.com.au/world/north-america/conspiracy-theories-are-new-currency-of-post-truth-politics-20190823-p52jyf.html.

Ball J. (2017). Post-Truth: How Bullshit Conquered the World. London: Biteback Publishing.

Barton R. and Whitehead J. (1969). 'The Gas-Light Phenomenon.' The Lancet 293, 1258-60.

Beerbohm E. and Davis R. (Forthcoming). 'Gaslighting Citizens.' American Journal of Political Science.

Behr R. (2018). 'On Brexit, the Tories Are Gaslighting Half the Country.' The Guardian, 10 August. https:// www.theguardian.com/commentisfree/2018/oct/08/brexit-tories-gaslighting-britain-pro-european.

Berkowitz J. (2016). 'Welcome To The Year In Post-Truth. Day One: Hillary, Trump, And The Birther Movement.' Fast Company, 1 December. https:/www.fastcompany.com/3066118/welcome-to-the-yearin-post-truth-day-one-hillary-trump-and-the-birth.

Blake-Turner C. (2020). 'Fake News, Relevant Alternatives, and the Degradation of Our Epistemic Environment.' Inquiry. Prepublished 10 February: 1-21. doi: 10.1080/0020174X.2020.1725623.

Caldwell A. (2016). 'How Russia Successfully Gaslighted the West.' Huffington Post, 16 December. https:// www.huffingtonpost.ca/adam-caldwell/the-gaslighting-of-the-west_b_13657466.html.

Carpenter A. (2018). Gaslighting America: Why We Love It When Trump Lies to Us. New York, NY: Harper.

Case S. (2019). 'The Boy Who Inflated the Concept of 'Wolf'.' Quillette, 14 February. https://quillette.com/ 2019/02/14/the-boy-who-inflated-the-concept-of-wolf/.

Cassam Q. (2019). Vices of the Mind: From the Intellectual to the Political. Oxford: Oxford University Press.

Cheney K. (2016). 'No, Clinton Didn't Start the Birther Thing. This Guy Did.' Politico, 16 September. https://www.politico.com/story/2016/09/birther-movement-founder-trump-clinton-228304.

Davies E. (2017). Post-Truth: Why We Have Reached Peak Bullshit. London: Little Brown.

Dowd M. (1995). 'Liberties; the Gaslight Strategy.' The New York Times, 26 November.

Duca L. (2016). 'Donald Trump Is Gaslighting America.' Teen Vogue, 12 October. https://www.teenvogue. com/story/donald-trump-is-gaslighting-america.

EUvsDisinfo. (2019). 'Tracing Five Years of Pro-Kremlin Disinformation about MH17.' EUvsDisinfo. 18 July. https://euvsdisinfo.eu/tracing-five-years-of-pro-kremlin-disinformation-about-mh17/.

Finlayson L. (2019). 'What to Do with Post-Truth.' Nordic Wittgenstein Review Special Issue, 63-79.

Fish W. (2016). 'Post-Truth' Politics and Illusory Democracy.' Psychotherapy and Politics International 14 (3), 211-13.

Fricker E. (2006). 'Testimony and Epistemic Autonomy.' In J. Lackey and E. Sosa (eds), The Epistemology of Testimony, pp. 225-50. New York, NY: Oxford University Press.

Fricker M. (2007). Epistemic Injustice: Power and the Ethics of Knowing. New York, NY: Oxford University Press.

Fricker M. (2017). 'Evolving Concepts of Epistemic Injustice.' In I.J. Kidd, J. Medina and G. Pohlhaus (eds), The Routledge Handbook of Epistemic Injustice, pp. 53-60. New York, NY: Routledge.

Gass G. and Nichols W. (1988). 'Gaslighting: A Marital Syndrome.' Contemporary Family Therapy 10, 3-16.

Habgood-Coote J. (2019). 'Stop Talking about Fake News!' Inquiry 62(9-10): 1033-65.

Hartwell-Walker M. (2018). ' 7 Ways to Extinguish Gaslighting.' Psychcentral, 18 December. https:/psychcentral.com/blog/7-ways-to-extinguish-gaslighting/.

Kahn B. (2019). 'Bolsonaro Is Trying to Gaslight the Entire World about Why the Amazon Is on Fire Right Now (Hint: It's Not NGOs).' Twitter, 21 August. https://twitter.com/blkahn/status/1164183934537785344.

Kristiansen L. and Kaussler B. (2018). 'The Bullshit Doctrine: Fabrications, Lies, and Nonsense in the Age of Trump.' Informal Logic 38, 13-52.

Laybats C. and Tredinnick L. (2016). 'Post Truth, Information, and Emotion.' Business Information Review 33(4), 204-6.

Levy N. (2017). 'The Bad News about Fake News.' Social Epistemology Review and Reply Collective 6, 20-36.

Democracy. I am grateful to Fleur Jongepier for extensive commentary on an early version. Special thanks go to Alfred Archer, Amanda Cawston, and Maureen Sie for invaluable feedback and guidance throughout this project. Finally, thank you to an anonymous reviewer and the editors at Episteme for their helpful suggestions. 
Lewandowsky S. (2019). 'Gaslighting: From Partners to Politicians - How to Avoid Becoming a Victim.' Metro News, 15 August. https://www.metro.news/gaslighting-from-partners-to-politicians-how-toavoid-becoming-a-victim/1675256/.

Nguyen C.T. (2020). 'Echo Chambers and Epistemic Bubbles.' Episteme 17(2), 141-61.

Pepp J., Michaelson E. and Sterken R. (2019). 'Why We Should Keep Talking about Fake News.' Inquiry. Published early online. doi: 10.1080/0020174X.2019.1685231.

Philips T. (2019). 'Jair Bolsonaro Says 'deceitful' Media Hyping Amazon Wildfires.' The Guardian, 24 September. https://www.theguardian.com/world/2019/sep/24/jair-bolsonaro-says-deceitful-media-hyping-amazon-wildfires.

Pool H. (2018). Bellingcat: Truth in a Post-Truth World. Documentary. https://www.bellingcatfilm.com/.

Rini R. (2017). 'Fake News and Partisan Epistemology.' Kennedy Institute of Ethics Journal 27, E43-64.

Ryan S. (2018). 'Epistemic Environmentalism.' Journal of Philosophical Research 43, 97-112.

Saul J. (2017). 'Racial Figleaves, the Shifiting Boundaries of the Permissible, and the Rise of Donald Trump.' Philosophical Topics 45, 97-116.

Spear A.D. (2019). 'Epistemic Dimensions of Gaslighting: Peer-Disagreement, Self-Trust, and Epistemic Injustice.' Inquiry. Published early online. doi: 10.1080/0020174X.2019.1610051

Stern R. (2007). The Gaslight Effect: How to Spot and Survive the Hidden Manipulations Other People Use to Control Your Life. New York, NY: Morgan Road Books.

Suiter J. (2016). 'Post-Truth Politics.' Political Insight 7(3), 25-27.

Sweet P. (2019). 'The Sociology of Gaslighting.' American Sociological Review 84(5), 851-75.

Ylä-Anttila T. (2018). 'Populist Knowledge: 'Post-Truth' Repertoires of Contesting Epistemic Authorities.' European Journal of Cultural and Political Sociology 5(4), 356-88.

Zagzebski L. (2012). Epistemic Authority: A Theory of Trust, Authority, and Autonomy in Belief. New York, NY: Oxford University Press.

Natascha Rietdijk is a $\mathrm{PhD}$ researcher in philosophy at Tilburg University and a member of the Tilburg Center for Moral Philosophy, Epistemology and Philosophy of Science. Her dissertation explores the effects of so-called "post-truth" politics on epistemic agency. Using insights from the ethics of manipulation and social epistemology, it describes the ways in which various contemporary socio-political practices influence relationships of epistemic trust. Her other research interests include political philosophy and moral psychology, especially issues relating to autonomy and authenticity.

Cite this article: Rietdijk N (2021). Post-truth Politics and Collective Gaslighting. Episteme 1-17. https:// doi.org/10.1017/epi.2021.24 